DOI https://doi.org/10.18551/rjoas.2017-12.49

\title{
FROM TRADITIONAL RECIPES TO BIOLOGICALLY COMPLETE FOOD PRODUCTS: REVIEW ON SNACKS EXTRUSION
}

\author{
Aksenova O.I. ${ }^{*}$, Post-graduate student \\ Alekseev G.V., Doctor of Technical Sciences \\ Krivopustov V.V., Yakovlev P.S., students \\ ITMO University, St. Petersburg, Russian Federation
}

\author{
Lobacheva N.N., Derkanosova A.A., Candidates of Engineering Sciences \\ VSUET University, Voronezh, Russia \\ *E-mail: oksi280491@yandex.ru
}

\begin{abstract}
Increasing consumption of light complete foods, convenient as fast food or snack foods, is one of the trends in the food market development. On the one hand, this trend associated with the healthy lifestyle popularization, and on the other hand, with the accelerated pace of modern society life. Thus, the energetic value of snack foods (snacks) is gradually replaced by requirements to their biological value. A highly efficient extrusion process allows producing biologically completed snacks with properties attractive to consumer.
\end{abstract}

\section{KEY WORDS}

Extrusion, snack products, technological process parameters, biological value, expanded snacks.

The accelerated rhythm of modern society life resulted in the popularity of fast food products. One of the most promising segments on the fast food market is the segment of snacks (snack foods).

Snacks are small lightweight quite simply cooked ready-to-eat foods. At the moment, the ability to satisfy the organoleptic feelings of the consumer is one of the most important quality indicators of snacks.

The entire assortment of snack foods can be divided into sweet (corn, popcorn, cookies, wafers, marmalade, chocolate bars) and salty (chips, extrudates, nuts, crisps, crackers, dried fish, jerky, smoked cheese and others) snacks.

The main criteria for snack foods are convenience of use, attractive appearance and texture, ease of adjusting the serving size.

Many researchers $[1,2]$ note the high content of sugar, salt and fats in snack foods, increased caloric content and biological incompleteness which affects human health negatively. Taking into account the worldwide growth of the popularity of healthy lifestyles, the demand for such "not healthy" snacks will decrease and for biologically complete snacks will grow.

It is possible to solve the above problems of snack foods incompleteness by combining the selection of recipe components and processing method.

The production of snack foods by extrusion is one of the most modern and perfect methods. Extrusion processing allows you to produce snacks with good organoleptic properties, which are so important for the consumer, without frying in oil, sugar panning or flavoring additives.

Extrusion of snack foods includes the influence of the prescription mixture of various complex physical processes on the ingredients: mixing, transporting, boiling and homogenizing at excess pressure. In the last stage, the treated mass is forced through the forming matrix and takes the form, texture and size that consumer expects to see [1].

Extrusion processing is becoming increasingly popular in comparison with traditional processing methods due to its automated control, high productivity, process continuity, 
flexibility and adaptability, energy efficiency, low cost.

The composition of snack foods can be reworked in such way that snacks still meet the requirements of high appeal to the consumer, but will contain ingredients that make them more complete.

Extruded snack foods consist mainly of cereals, starches, and / or plant and animal proteins. The main role of these ingredients is to provide the necessary structure, texture, taste and density [2].

Wheat, rice, corn or barley flour and their combinations with accompanying products of vegetable, fish and meat processing are used in the production of extruded snacks.

Rice flour is an attractive base ingredient for the production of extruded snacks due to its unique properties, such as soft taste, attractive white color, hypoallergenicity and good digestibility. At present, there is large number of research on the extrusion of rice flour for the production of snacks [2, 3].

One of the most cultivated starch cultures in Russia and Belarus is potato, but the process of extruding potatoes for the production of snack foods around the world is not studied well enough, the research studies of Nath and Chattopadhyay, Cheyne, Barnes, Nenakhov R.V. and Ostrikov A.N. are devoted to this problem [4-7].

Another common ingredient of extruded snacks is legumes. They provide a good extrudate expansion and are considered the valuable source of protein [6-8]. For the legumes the advantages of extrusion are particularly important - partial or complete inactivation of some anti-nutrient compounds that limit the wide use of legumes.

Sucrose is a standard additive to sweet extruded snack foods and is included in these products in a ratio of up to $50 \%$ by weight. However, a number of researchers $[2,9]$ note that even low sucrose concentrations (up to $12 \%$ ) in the presence of moisture (20\%) significantly reduce the expansion, increase the mechanical strength of the extrudate and dough viscosity.

At present, the development of recipes for snacks enriched with valuable nutrients, but not of high cost is especially relevant. This is achieved by adding to the recipe accompanying products of processing fruits, berries and vegetables, as sources of minerals, vitamins and dietary fibers.

Thus, in snacks enriched with dietary fiber from vegetable and fruit waste $[10,11]$ higher content of dietary fibers, better ratio of soluble and insoluble fibers than in snacks enriched with dietary fiber from cereal bran was noted. Some researchers [12] studied the addition of waste from tomato processing to traditional starch extruded snacks. Also, Stojceska [13] found out that the addition of spent brewing malt increases the protein and phytic acid content significantly and reduces the expansion index.

The recipes of modern snacks are quite diverse due to the fact that extrusion makes it possible to adjust the traditional grain recipes of snacks easily, enriching them with valuable food substances from raw materials rich in proteins and dietary fibers including the accompanying product of other food products processing.

Extrusion processing of food products has been used for more than 50 years. Nowadays the range of extruded food products includes more than 400 items and snack foods is one of them [2].

Extrusion is the process of forcing material to flow under various process parameters through a forming hole (matrix) at a given speed [1].

At present, the following types of extrusion are distinguished: cold - it is characterized only by mechanical influence on raw materials by humidity of $30-60 \%$; warm - it is characterized by mechanical and thermal impact on the raw material moistened to $20-30 \%$, as a result, a low-density extrudate (unexpanded pellets) is formed; hot - it is characterized by a significant transfer of mechanical energy into thermal energy, high speeds and pressures, regular supply of heat from external sources, accompanied by deep estates of quality raw materials with the moisture content of 10-20\% (expanded snacks) [7, 14].

Raw materials processing for snack products by extrusion methods is caused by a high economic effect, which is achieved by replacing the large complex of production equipment with one machine i.e. extruder [7]. Nowadays extruders are considered as high-temperature, 
short-term bioreactors, which convert raw ingredients into modified semi-finished products and finished products.

In the extrusion process, thermal and shear energies are applied to the raw material causing structural and chemical transformations, changes in the biological value of the product. If you analyze these changes in more detail, you can identify that during the extrusion process there is breakdown of starch grains, starch gelatinization, denaturation of proteins, fat oxidation, destruction of vitamins, antioxidants, phytochemicals, flavoring, increased mineral bioavailability and solubility of dietary fibers. Extrusion helps to modify the structure, improve solubility and swelling, viscosity, water conservation capacity [1, 15].

Characteristic of extruded starch snacks microstructure shows that the raw material underwent macromolecular destruction, reflected as a change in melt rheology and functional properties of the product such as water absorption, water solubility, dispersion viscosity, oil absorption index, bulk density, expansion index and dough viscosity [16].

It is important to understand that in products, where the consumer wants to see the expanded structure, the texture is most important and the crunchiness becomes one of the most important attributes [3].

Mechanical properties of extruded snacks are also one of the key quality indicators; they determine the convenience of consumption, storage and transportation of snacks [10].

The water absorption index (WAI) and water solubility index (WSI) characterize how extruded products will interact with water and are important in predicting the behavior of the material if it is subjected to further processing.

In the process of snacks extrusion, expansion is critically important feature describing the quality of the product and directly related to the degree of its readiness. Numerous theories and models were proposed to describe extrudate expansion [10,17]. The increase in bulk density is connected with decrease in the expansion coefficient and vice versa. Expansion of the extrudate depends to the greatest extent on the moisture content of the material and the extrusion temperature. Extension of the extrudate was investigated by Zhu L.J. and Wang N. [16, 18], also general extrudate expansion model was developed by Cheng $\mathrm{H}$., including radial, longitudinal and volumetric extensions [17]. In most of these studies, radial expansion was used as a measure of the quality of extrudate expansion.

Thermal and mechanochemical effects that occur during extrusion change the rheological properties of the raw materials. In works $[10,18,19]$, the effect of moisture content in raw materials, the presence of additives and operating conditions of the extruder on the viscosity characteristics of extruded snacks were studied.

The composition and humidity of the compound mixture, temperature, pressure, duration and intensity of its exposure are variable parameters in the process of extruded snacks production.

The temperature of the extruder body is an important parameter that determines the quality of the extruded product. In the study [18,19], the temperature in the last two zones and the speed of feed auger were selected as varying operating parameters of the process, while the mixture moisture and feed rate were maintained at constant level. It was found that simultaneous increase in the temperature and velocity of the auger leads to expansion coefficient increase and decrease in the bulk density and shear tension. Number of scientists note that the high moisture level of mixture in combination with high temperature leads to increase in density and hardness, decrease in the expansion coefficient of chickpea [17] and corn [19] snacks.

The moisture content is also one of the key parameters of the extrusion process, since it determines the texture, color and snacks expansion coefficient. In studies [1,20], it was found that the increased moisture content of the mixture reduces the radial expansion ratio of the extrudates, which results in a higher apparent density, tensile strength and lower porosity values. Cupta studied the effect of feed rate, humidity of the mixture and the temperature of the extruder body on the various extrudate characteristics, and scientists found that the moisture content of the raw materials had the greatest impact [12].

It was established that the size of the raw material particles is also the factor determining the structure of the snack. Thus, the soft texture of product is the consequence 
of the fine granulation of raw material, and the crunchy texture is the consequence of large granulation [21].

Satisfaction with the ever-changing demands of the food market requires a continuous improvement in the technology of production and searching new ingredients, including products connected with the processing of other types of food raw materials. Extrusion processing for the production of snack foods as environmentally safe, resource-saving and universal process that allows to obtain well-assimilated, heat-sterilized food products with improved taste properties, causes in this sense especially close attention.

Extrusion is currently one of the most effective ways to develop products with balanced recipes and allows them to be easily enriched with proteins, vitamins, food fibers. So it seems advisable to solve actual problems with this technology - to create snack foods that don't have disadvantages of traditional fast food, that is, to ensure the production of snack foods with regulated food, biological and energy values [5].

\section{REFERENCES}

1. Alam M.S., Kaur J., Khaira H., Cupta K. Extrusion and extruded products: changes in quality attributes as affected by extrusion process parameters: a review / Critical reviews in food since and nutrition - №56 - 2016. - pp. 445-473.

2. Ostrikov AN, Sokolov I.Y., Vasilenko V.N. Co-extrusion products: new approaches and prospects. Moscow: Deli-Print - 2009. - 232 p.

3. Saeleaw M., Durrschmid K., Schleining, G. The effect of extrusion conditions on mechanical-sound and sensory evaluation of rye expanded snack/ Journal of Food Engineering - 2012. - №110(4) - pp. 532-540.

4. Nayak B., Liu R.H., Berrios J.D.J., Tang J. Bioactivity of antioxidants in extruded products prepared from purple potato and dry pea flours / Journal of Agricultural and Food Chemistry - 2011. - №15 - pp. 8233-8243.

5. Zambano-Zaragoza M.L. Effect of extrusion process in snaks of oast-nixtamalized corn pericarp mixtures on dietary fiber content and functional properties/ CyTA - Journal of Food - №1 - 2013. - pp. 38-45.

6. Ostrikov AN, Abramov OV, Rudometkin AS Extrusion in food technologies. Monograph. SPb.: GIORD - 2004. - 288 p.

7. Pastor-Cavada E., Drago S.R., Gonzalez R.J. Effects of the addition of wild legumes (Lathyrus annuus and Lathyrus clymenum) on the physical and nutritional properties of extruded products based on whole corn and brown rice/ Food Chemistry - 2011. - №128 pp. 961-967.

8. Delgado-Nieblas C.I., Zazueta-Morales J.J. Elaboration of functional snack foods using raw materials rich in carotenoids and dietary fiber: effect of extrusion processing/ CyTA Journal of Food. - №1 - 2015. - pp. 69-79.

9. Karkle E. L., Keller L., Dogan H., Alavi S. Matrix transformation in fiber-added extruded products: Impact of different hydration regimens on texture, microstructure and digestibility/Food Engineering -2012. - №108 - pp. 171-181.

10. Robin F., Dubois C., Curti D. Effect of wheat bran on the mechanical properties of extruded starchy foams/ Food Research International - 2011. - №44(9) - pp. 2880-2888.

11. Shoar Z.D. The physico-chemical characteristics of extruded snacks enriched with tomato lycopene/ Food Chemical- 2010. - №123 - pp. 1117-1122.

12. Stojceska V., Ainsworth P., Plunkett A. The advantage of using extrusion processing for increasing dietary fibre level in gluten-free products/ Food Chemistry - 2010. - №121 pp. 156-164.

13. Sushkova VI, Vorobyova G.I. Wasteless conversion of plant raw materials into biologically active substances. Kirov - 2007. - 204 p.

14. Camacho-Hernandez I.L. Effect of extrusion conditions on physicochemical characteristics and anthocyanin content of blue corn third-generation snacks/ CyTA Journal of Food - 2014. - №12(4) - pp. 320-330.

15. Zhu L.J. Mechanical and microstructural properties of soy protein-high amylose corn 
starch extrudates in relation to physiochemical changes of starch during extrusion/ Journal of Food Engineering - 2011. - №100 - pp. 232-238.

16. Cheng $\mathrm{H}$., Friis A. Modelling extrudate expansion in a twin-screw food extrusion cooking process through dimensional analysis methodology/ Food Bioprocess Technology - 2011. - №88 - pp. 188-194.

17. Wang N., Maximiuk L. Pea starch noodles: Effect of processing variables on characteristics and optimisation of twin-screw extrusion process/ Food Chemistry - 2012. - №133 - pp. 742-753.

18. Camacho-Hernandez I.L. Effect of extrusion conditions on physicochemical characteristics and anthocyanin content of blue corn third-generation snacks/ CyTA Journal of Food - 2014. - №12(4) - pp. 320-330.

19. Cheyne A. Extrusion behavior of cohesive potato starch pastes: II. Microstructureprocess interactions/Journal of Food Engineering - 2005. - №66 - pp. 13-24.

20. Meng X., Threinen D., Hansen M., Driedger, D. Effects of extrusion conditions on system parameters and physical properties of a chickpea flour-based snack/ Food Research International - 2012 -№43 - pp. 650-658. 